\title{
Photocatalytic Degradation of Organic Dye by Sol-Gel-Derived Gallium-Doped Anatase Titanium Oxide Nanoparticles for Environmental Remediation
}

\author{
Arghya Narayan Banerjee, ${ }^{1}$ Sang Woo Joo, ${ }^{1}$ and Bong-Ki Min ${ }^{2}$ \\ ${ }^{1}$ School of Mechanical Engineering, Yeungnam University, Gyeongsan 712-749, Republic of Korea \\ ${ }^{2}$ Center for Research Facilities, Yeungnam University, Gyongsan 712-749, Republic of Korea
}

Correspondence should be addressed to Arghya Narayan Banerjee, banerjee_arghya@hotmail.com and

Sang Woo Joo, swjoo@yu.ac.kr

Received 20 January 2012; Revised 12 March 2012; Accepted 13 March 2012

Academic Editor: Vo-Van Truong

Copyright (C) 2012 Arghya Narayan Banerjee et al. This is an open access article distributed under the Creative Commons Attribution License, which permits unrestricted use, distribution, and reproduction in any medium, provided the original work is properly cited.

\begin{abstract}
Photocatalytic degradation of toxic organic chemicals is considered to be the most efficient green method for surface water treatment. We have reported the sol-gel synthesis of Gadoped anatase $\mathrm{TiO}_{2}$ nanoparticles and the photocatalytic oxidation of organic dye into nontoxic inorganic products under UV irradiation. Photodegradation experiments show very good photocatalytic activity of Ga-doped $\mathrm{TiO}_{2}$ nanoparticles with almost $90 \%$ degradation efficiency within $3 \mathrm{hrs}$ of UV irradiation, which is faster than the undoped samples. Doping levels created within the bandgap of $\mathrm{TiO}_{2}$ act as trapping centers to suppress the photogenerated electron-hole recombination for proper and timely utilization of charge carriers for the generation of strong oxidizing radicals to degrade the organic dye. Photocatalytic degradation is found to follow the pseudo-first-order kinetics with the apparent 1storder rate constant around $1.3 \times 10^{-2} \mathrm{~min}^{-1}$. The cost-effective, sol-gel-derived $\mathrm{TiO}_{2}$ : Ga nanoparticles can be used efficiently for light-assisted oxidation of toxic organic molecules in the surface water for environmental remediation.
\end{abstract}

\section{Introduction}

Titanium dioxide $\left(\mathrm{TiO}_{2}\right)$ is one of the most important wide bandgap metal oxides which is having a vast range of applications from paint to sunscreen to food coloring to photocatalyst, hydrogen production, storage medium, sensors, solar cells, organic waste management, and various biological and health-related applications [1-13]. Because of its wide range of properties, $\mathrm{TiO}_{2}$ bulk films as well as nanostructured materials become the subject of intense research within the global scientific community. In general, $\mathrm{TiO}_{2}$ has two stable crystalline structures: anatase and rutile [14]. Rutile is preferred to anatase for optical applications because of its higher refractive index, whereas anatase is preferred for all the applications related to photocatalytic activity, gas sensing, and solar cells, due to its higher mobility and catalytic properties $[15,16]$.

Amongst various $\mathrm{TiO}_{2}$ nanostructures, titania nanoparticles have specific advantages in the enhancement of light absorption due to the large fraction of surface atoms. Interband electron transition is the primary mechanism of light absorption in pure semiconductors. These transitions are direct as the momentum gain by the electron from light wave is small in comparison with $\pi h / a$ (" $a$ " is the lattice constant). This absorption is small in direct-forbidden gap semiconductors, as in the case for $\mathrm{TiO}_{2}$, for which the direct electron transitions between the band centers are prohibited by the crystal symmetry. However, momentum is not conserved if the absorption takes place at the boundary of the crystal, for example, at the surface or at the interface between two crystals, which leads to the indirect electron transitions that can result in the essential enhancement of light absorption. This means that considerable enhancement of the absorption can be observed in small nanocrystals where the surface-to-volume ratio is very high and the fraction of the surface atoms is sufficiently large. The particle size at which the interface enhancement of the absorption becomes significant is around $20 \mathrm{~nm}$ or less. An additional advantage obtained in nanoparticles in the few nanometer 
size regimes is that the large surface-to-volume ratio makes possible the timely utilization of photogenerated carriers in interfacial processes $[1,17]$. Additionally, the doping of $\mathrm{TiO}_{2}$ nanoparticles is performed for improved photocatalytic activities by reducing the band gap of $\mathrm{TiO}_{2}$ to utilize the wider fraction of solar radiation, especially the visible and near infrared (NIR) parts [4, 18-20]. Many efforts have been expended to narrow the $\mathrm{TiO}_{2}$ band gap by substitutional doping. According to the crystal structure of $\mathrm{TiO}_{2}$, it appears that replacement of $\mathrm{Ti}^{4+}$ with any cation is relatively easier than to substitute $\mathrm{O}^{2-}$ with any other anion due to the difference in the charge states and ionic radii. Cationic doping of $\mathrm{TiO}_{2}$ with transition and rare earth metals has been extensively studied [18-24]. While several authors have reported that transition metal ion doping decreases the photothreshold energy of $\mathrm{TiO}_{2}$, there is also an increase in thermal instability and a decrease in carrier lifetimes [25], which limits overall conversion efficiencies. Therefore, it is clear that there is always scope for improvement in the photoactivity of $\mathrm{TiO}_{2}$ nanostructures either by applying various new dopants or (and) adopting different doping parameters through different deposition processes and conditions. Amongst various photocatalytic applications of $\mathrm{TiO}_{2}$, photocatalytic degradation of toxic organic chemicals (especially organic dyes generated as industrial wastes and released in the surface water without proper treatment) is considered to be the most efficient green method for organic waste management in terms of photosensitized $\mathrm{TiO}_{2}$-assisted oxidation of organic pollutants for surface water treatment, recovery of precious metals via $\mathrm{TiO}_{2}$-assisted reduction, organic synthesis, photokilling activity, and self-cleaning activity among others [26-35].

As far as the syntheses of undoped and doped $\mathrm{TiO}_{2}$ nanostructures are concerned, both solution-based chemical techniques as well as vacuum-based physical techniques $[1,7$, 9] have been adopted. In the current study, we have reported the sol-gel syntheses and characterizations of Ga-doped anatase $\mathrm{TiO}_{2}$ nanoparticles $\left(\mathrm{TiO}_{2}: \mathrm{Ga}\right)$ and investigated the photocatalytic oxidation of organic dyes for environmental remediation. Apparently, sol-gel deposition process is preferred (at least in the research scale) over vacuumbased as well as hydrothermal syntheses, mainly because of its simplicity and cost-effectiveness in terms of materials, design, process, and implementation. As far as the reason behind the adoption of $\mathrm{Ga}$ as the doping material is concerned, previously few authors reported the improved photocatalytic activities of $\mathrm{TiO}_{2}: \mathrm{Ga}$ (and $\mathrm{TiO}_{2}: \mathrm{Ga} / \mathrm{I}$ codoped) nanomaterials in terms of solar hydrogen production and photodecomposition of various organic compounds used in disinfectants and pesticides [36-41]. The comparable ionic radii of $\mathrm{Ta}^{+4}(68 \mathrm{pm})$ and $\mathrm{Ga}^{+3}(62 \mathrm{pm})$ appears to be favorable for the substitutional doping of Ga atoms into the Ti matrix to improve the optical, electronic, and photocatalytic properties. To best of our knowledge, no report has been published on the photocatalytic oxidation of organic dyes by anatase $\mathrm{TiO}_{2}$ : Ga nanoparticles for organic waste treatments, which is one of the burning issues in the industrial waste management and, hence, needs much attention.
As far as the difference between our work against the previously reported sol-gel-derived Ga-doped (or Ga/I codoped) $\mathrm{TiO}_{2}$ nanomaterials is concerned $[37,38]$, both of these reports indicated the formation of phase impure $\mathrm{TiO}_{2}$ nanopowders with a mixture of anatase and rutile (as well as a small fraction of brookite) phases under $\mathrm{Ga}$ (or $\mathrm{Ga} / \mathrm{I}$ ) (co-)doping, whereas we have been able to obtain phase pure anatase $\mathrm{TiO}_{2}$ nanoparticles (as shown later) via our solgel route. It has been reported previously that phase pure anatase $\mathrm{TiO}_{2}$ (along with commercially available Degussa $\mathrm{P}-25)$ has the highest hydroxyl radical $\left({ }^{\circ} \mathrm{OH}\right)$ formation rate under photoirradiation, which is considered to be the main species responsible for the photooxidation of organic compounds [10]. Therefore, it is desirable to synthesize phase-pure anatase $\mathrm{TiO}_{2}$ for efficient photodegradation of organic molecules, and, in that respect, our process to synthesize phase-pure Ga-doped anatase $\mathrm{TiO}_{2}$ nanoparticles may become very important for efficient photocatalytic organic waste management. Also, for the application of waste water treatment via $\mathrm{TiO}_{2}$ : Ga-based photocatalytic degradation of organic molecules, photocatalytic oxidation of water soluble organic dyes (like Rhodamine B, as in our case) should be preferred as the testing agent against sparingly soluble organic substances (like 2-chlorophenol, 1,4 -dichlorobenzene, and so forth, as used in $[37,38]$ ), because the water soluble toxic dyes released from textile industries in the surface water as waste products pose considerable threats to the environment and, hence, warrants proper attention.

\section{Experimental}

2.1. Materials. Undoped and Ga-doped anatase $\mathrm{TiO}_{2}$ nanopowders were synthesized by the sol-gel route using titanium isopropoxide [ $\left.\mathrm{Ti}\left\{\mathrm{OCH}\left(\mathrm{CH}_{3}\right)_{2}\right\}_{4}\right]$ and gallium(III) oxide $\left(\mathrm{Ga}_{2} \mathrm{O}_{3}\right)$, (all from Sigma Aldrich, Korea, $99.9 \%$ pure) as $\mathrm{Ti}$ and $\mathrm{Ga}$ sources, respectively. Isopropanol, acetic acid (99.0\%, Duksan Pure Chemicals, Republic of Korea), and deionized (DI) water is used for precursor solution preparation. For photocatalytic experiment, Rhodamine B ( $\mathrm{R}^{\mathrm{h}} \mathrm{B}$, Sigma Aldrich, Republic of Korea) is used as the organic dye in the aqueous solution.

2.2. Method. Firstly, $0.05 \mathrm{~mol}$ of titanium isopropoxide is dissolved into isopropanol with a 1:10 molar ratio, respectively. In order to stabilize the Ti solution, acetic acid is then added to the solution until the $\mathrm{pH}$ of the solution is in between 3.0 and 3.5. The resulting solution is stirred for $60 \mathrm{~min}$ at room temperature until a homogeneous sol is prepared. Then, the sol is aged for $24 \mathrm{hrs}$ at ambient condition to get the gel. Thereafter, the gel is air-dried at $100^{\circ} \mathrm{C}$ to remove the solvents. The dried gels are then calcined in air ambient at $700^{\circ} \mathrm{C}$ (in a furnace, Thermo Fisher Scientific, Republic of Korea) for $2 \frac{1}{2}$ hours to get the nanocrystalline powder which is then grounded in an agate mortar to get $\mathrm{TiO}_{2}$ nanoparticles. For the syntheses of Gadoped $\mathrm{TiO}_{2}, 1.0$ at.\% $\mathrm{Ga}$ doping are performed in the nominal solution by dissolving stoichiometric amounts of $\mathrm{Ga}_{2} \mathrm{O}_{3}$ 
in $0.4 \mathrm{~mol}$ isopropanol and deionized water (with $10: 1$ molar ratio) and stirred for $30 \mathrm{~min}$ at room temperature. This doping solution is then added to the Ti sol prepared by above-mentioned msheethod and stirred for $60 \mathrm{~min}$ at room temperature followed by doped sol preparation and corresponding gelation as mentioned above. The layout of the deposition process is furnished in Figure 1.

The probable chemical reactions taking place at different stages of the sol-gel process are furnished as sources.

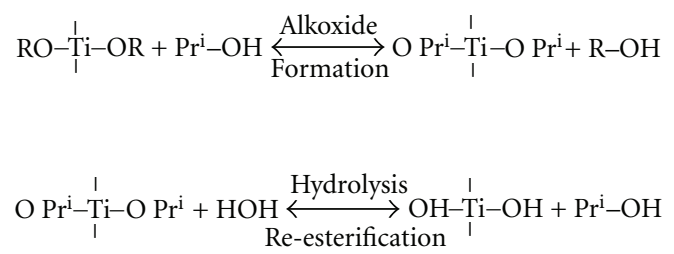

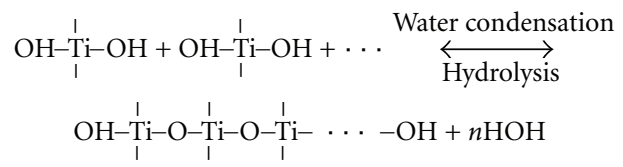

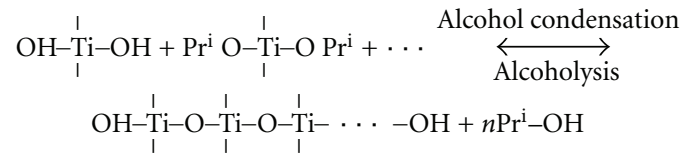

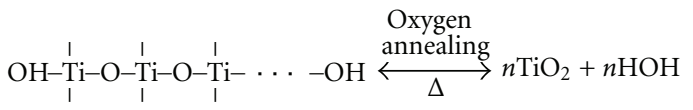

Titanium isopropoxide (Ti-OR) is reacted with isopropyl alcohol $\left(\mathrm{Pr}^{i}-\mathrm{OH}\right)$ to form alkoxide which is then hydrolyzed to form $\mathrm{Ti}-\mathrm{OH}$, followed by condensation to get Ti-O-Ti group along with the by-products of water and alcohol. This produces the sol, which is then aged to get long chains of ... Ti-O-Ti-O-Ti-O-. . . terminated by hydroxyl groups, resulting in the thickening of the sol to form the gel. Finally, the gel is dried and calcined in oxygen (or air) atmosphere to get $\mathrm{TiO}_{2}$.

2.3. Characterizations. The structural properties of the assynthesized undoped and $\mathrm{Ga}$-doped $\mathrm{TiO}_{2}$ nanoparticles are studied by X-ray diffractometer (XRD, Philips XPertPowder) and Raman spectroscopy (Confocal Raman Microscope, Model number alpha300R, WITec, Germany) with excitation of $532 \mathrm{~nm}$. Microstructural analysis of the nanoparticles is performed by scanning transmission electron microscope (STEM, Tecnai G ${ }^{2}$ F20). For high-resolution (HR) TEM characterizations, the nanoparticles are dispersed in alcohol, followed by stirring and drop casting onto the $\mathrm{C}$-coated $\mathrm{Cu}$ grid and drying. Optical diffuse reflectance measurements are performed by using a UV-Vis-NIR spectrophotometer (Shimadzu UV-160A) in the spectral range of 300 to
$2500 \mathrm{~nm}$. X-ray photoelectron spectroscopic (XPS, K-Alpha, Thermo Fisher Scientific, Republic of Korea) measurements are done by using X-ray $\mathrm{Al} \mathrm{K}_{\alpha}$ source. The wide range survey spectra are carried out within the binding energy (B.E.) range of 0.0 to $1350.0 \mathrm{eV}$ with a pass energy of $200.0 \mathrm{eV}$, whereas the high resolution spectra for $\mathrm{O} 1 \mathrm{~s}$, Ti 2p, Ga $3 \mathrm{~d}$ electronic structures are measured with a $50.0 \mathrm{eV}$ pass energy.

2.4. Photocatalytic Characterization. The photocatalytic activity of Ga-doped $\mathrm{TiO}_{2}$ is performed by recording the degradation of $\mathrm{R}^{\mathrm{h}} \mathrm{B}$ in aqueous solution under $\mathrm{UV}$ radiation. The home-built photoreactor consists of two 16 W UV tube (Fisher Scientific, Republic of Korea) using $254 \mathrm{~nm}$ wavelength placed $8 \mathrm{~cm}$ away from the reaction vessel containing the dye solution. Before reaction, the dye solution $(50 \mathrm{~mL})$ is prepared by mixing $\mathrm{R}^{\mathrm{h}} \mathrm{B}$ and DI water in a molar ratio of $3.6 \times 10^{-6}: 1$ and stirred by a magnetic stirrer (Fisher Scientific, Republic of Korea) for $45 \mathrm{~min}$ in dark condition to ensure the proper adsorption-desorption equilibrium of dye molecules on the nanoparticle surfaces to act as efficient photocatalysts. The organic dye degradation experiment is performed at different times to observe the decrement in the dye concentration by taking digital photographs of the solution until the whole solution is decolored to ensure complete degradation of the dye molecules. To determine the dye concentration within the degraded solution, UV-Vis spectrophotometric measurements (Shimadzu UV-160A) of the dye solution oxidized at different times are performed within the spectral range of 300 to $800 \mathrm{~nm}$. Before the optical measurements, the dye is separated from the nanoparticles by centrifuging the solution for $10 \mathrm{~min}$ (Model 1-14, Sigma, Germany).

\section{Results and Discussion}

3.1. XRD and HRTEM Analyses. XRD analyses of undoped and $\mathrm{Ga}$-doped $\mathrm{TiO}_{2}$ nanoparticles are shown in Figure 2(a). The peaks show the formation of anatase $\mathrm{TiO}_{2}$ with $\mathrm{I}_{1} /$ amd space group (1999 JCPDS ICCD File Card nymber 83-2243). No peaks of initial constituents and any by-product have been observed for our samples to confirm the formation of phase pure anatase $\mathrm{TiO}_{2}$ nanomaterials along with the proper doping within the Ga-doped sample. It has been observed that the peak intensities of both the patterns are almost similar, whereas the full width at half maxima (FWHM) of the peaks of undoped sample are slightly lesser than that of doped one. Especially, the broad peak between $36^{\circ}$ to $40^{\circ}$ is found to be fairly resolved in the undoped sample (as shown in Figure 2(b) through deconvolution) into three distinct peaks ((103), (004), and (112)), whereas the doped sample shows a broad hump around $37.8^{\circ}$. Similarly, the well-resolved $(105) /(211)$ and $(116) /(220)$ peaks in the undoped sample tend to merge in the doped sample. Also a relative comparison of the (101) peaks of as-synthesized undoped and metal-doped samples (cf. Figure 2(c)) reveals that the FWHM increases in the doped sample against undoped samples, with the peak positions remaining almost identical (and this trend is valid for all 


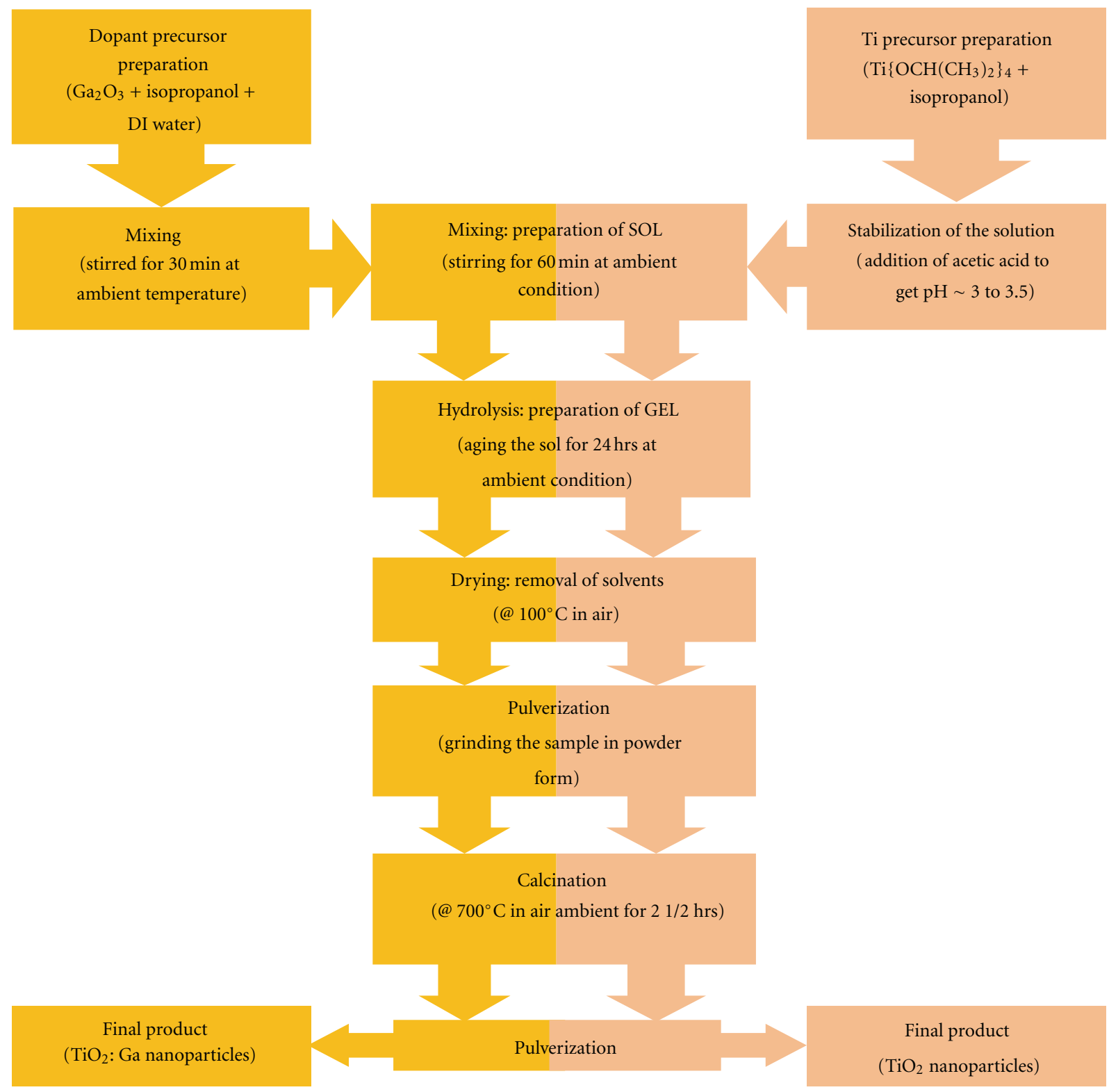

Figure 1: Flow chart of the sol-gel syntheses of undoped and Ga-doped $\mathrm{TiO}_{2}$ nanoparticles. Two different colors are used to separate the doping processes from the nondoping case.

other peaks of the samples as well). It is well-known that "particle-broadening effect" generally increases the FWHMs of the diffraction peaks in nanoparticles [42]. But the HRTEM imaging reveals (shown later) that the particle sizes for both undoped and doped samples are almost similar, indicating negligible size effect within the samples. Therefore, it is speculated that "strain-broadening" is highly effective in the as-synthesized doped samples for the relative increment in the FHHMs of the XRD peaks. Generally, in a polycrystalline aggregate, the individual crystallites in a grain is not free to deform in the same way as an isolated crystal would, if subjected to the same deforming force. As a result of this restraint by its neighbors, a grain in a polycrystalline aggregate is usually in a state of tension or compression, which produces uniform or nonuniform strain within the sample and reflected either by a shift in the diffraction peaks (for uniform strain) or by a peak broadening (also called "strain-broadening" for nonuniform strain) without changing the peak position [42]. As mentioned earlier, the ionic radius of $\mathrm{Ti}^{+4}$ is $68 \mathrm{pm}$, whereas the same for $\mathrm{Ga}^{+3}$ is $62 \mathrm{pm}$. Apparently, the doping of $\mathrm{Ga}^{+3}$ into lattice $\mathrm{Ti}^{+4}$ sites (substitutional doping) as well as in the interstitial sites creates nonuniform strain within the doped samples which is reflected in the peak-broadening effect of the XRD peaks of $\mathrm{TiO}_{2}$ : Ga nanopowders. To quantitatively determine the effective crystallite size, $L_{\text {cryst }}^{\text {eff }}$ and strain, $\varepsilon^{\text {eff }}$ within 
the undoped and metal-doped samples, the FWHMs $(\beta$, measured in radian) of the XRD peaks for different $2 \theta$ values are expressed as

$$
\frac{\beta \cos \theta}{\lambda}=\frac{1}{L_{\text {cryst }}^{\text {eff }}}+\frac{\varepsilon^{\text {eff }} \sin \theta}{\lambda},
$$

where $\lambda$ is the incident $\mathrm{X}$-ray wavelength (1.5406 $\AA$ ). A plot of $\beta \cos \theta / \lambda$ versus $\sin \theta / \lambda$ will be a straight line, slope of which will give the estimation of the effective strain, whereas the intercept on $\beta \cos \theta / \lambda$ axis will carry the information of the effective crystallite size. Figure 2 (d) shows the size-strain analysis plots of undoped and $\mathrm{Ga}$-doped $\mathrm{TiO}_{2}$ samples and reveal the average crystallite sizes around 10.0 to $12.0 \mathrm{~nm}$, whereas the strain increases from $7.53 \times 10^{-3}$ (for undoped samples) to a maximum of $2.71 \times 10^{-2}$ (for Ga-doped samples), which is consistent with the above discussions regarding the increasing trend of FWHMs between undoped and doped samples. A comparison between size-strain values for two types of samples is furnished in Table 1 .

Figures 3(a) to 3(d) show the HRTEM micrographs of undoped and $\mathrm{Ga}$-doped $\mathrm{TiO}_{2}$ nanoparticles for two different magnifications. High-mag images show the proper lattice spacing of $\mathrm{TiO}_{2}$. The insets of Figures 3(a) and 3(c) represent the corresponding size distributions of as-synthesized nanoparticles. The sizes are calculated from the image analysis of the micrographs assuming the particle area to be the projection of spherical particles. The average particle sizes $\left(L^{\text {avg }}\right)$ are obtained as $15.3 \mathrm{~nm}$ (undoped $\mathrm{TiO}_{2}$ ) and $17.8 \mathrm{~nm}\left(\mathrm{TiO}_{2}: \mathrm{Ga}\right)$, respectively, and consistent with the crystallite size calculations from XRD data (Figure 2(d)) for polycrystalline nanoparticles. Also the insets of Figures 3(b) and 3(d) represent the selected area electron diffraction (SAED) patterns of the samples indicating the characteristics circles originating from the corresponding crystals planes of anatase $\mathrm{TiO}_{2}$. Figure 4 shows the EDX data of undoped and metal-doped $\mathrm{TiO}_{2}$ nanoparticles indicating the presence of elemental constituents within the as-synthesized samples. The atomic percentages of $\mathrm{Ti}, \mathrm{O}$, and $\mathrm{Ga}$ are furnished in Table 1.

3.2. XPS Analyses. The chemical and electronic structures of as-synthesized undoped and metal-doped samples are determined by XPS analysis and shown in Figure 5. Figure 5(a) shows the high-resolution XPS spectra of undoped and metal-doped $\mathrm{TiO}_{2}$ nanoparticles of $\mathrm{O}$ 1s region, which, after deconvolution, can principally be assigned to lattice oxygen $\left(\mathrm{Ti}^{x}-\mathrm{O}: x=+3,+4\right)$ and surface-adsorbed hydroxyl groups (Ti-OH). Table 2 lists the results of curve fitting of XPS spectra for undoped and metal-doped $\mathrm{TiO}_{2}$. As seen in the table, the Ti-O peaks are formed at a binding energy (B.E.) around $530.5 \mathrm{eV}$ for all the samples, which is slightly blueshifted $(+0.7 \mathrm{eV})$ from the standard value of $\sim 529.8 \mathrm{eV}[40]$. Similar kinds of blue-shifts are reported by others $[43,44]$ as well and attributed to the presence of larger number of surface hydroxyl groups within the samples. In our case also, the comparatively higher percentage of $\mathrm{Ti}-\mathrm{OH}$ concentration against previously reported values $(8.0-25.0 \%)$ [40, 45] clearly depicts the higher $\mathrm{OH}^{-}$-terminated surface in our samples and may be attributed to the higher surface-tovolume ratio in our nanoparticles that created larger number of surface adsorption sites for hydroxyl ions. Also the relative concentrations of $\mathrm{Ti}-\mathrm{OH}$ peaks are found to increase in the Ga-doped sample against undoped one, suggesting that the Ga-doped $\mathrm{TiO}_{2}$ enhances the adsorption of $\mathrm{OH}^{-}$ ions, which consequently increases the hydrophilicity of the nanoparticles [43]. As far as the photocatalytic activity is concerned, it has been reported that the so-called surface "titanol" groups ( $\mathrm{Ti}-\mathrm{OH})$ in $\mathrm{TiO}_{2}$ photocatalysts act as the hole scavenger to form the main oxidizing site to improve the photoactivity of $\mathrm{TiO}_{2}$ [44]. Therefore, Ga-doped $\mathrm{TiO}_{2}$ with higher $\mathrm{Ti}-\mathrm{OH}$ concentration is expected to produce larger number of hydroxyl groups to enhance its photocatalytic activity during photolysis. Also, the substitution of a $\mathrm{Ga}^{+3}$ into $\mathrm{Ti}^{+4}$ sites will create oxygen vacancy, which serves as an electron trap and effectively enhances the lifetime of the hole, which, in turn, helps in the oxidative degradation of pollutants. As far as the presence of $\mathrm{Ti}^{+4}$ states in the as-synthesized samples is concerned, Figure 5(b) shows the typical high-resolution spectra of undoped and Ga-doped $\mathrm{TiO}_{2}$ nanoparticles, indicating the spin-orbital splitting of Ti $2 p_{3 / 2}$ and $\mathrm{Ti} 2 \mathrm{p}_{1 / 2}$ photoelectrons in anatase $\mathrm{TiO}_{2}$ at B.E. values around $459.3 \mathrm{eV}$ and $465 \mathrm{eV}$, respectively. The FWHMs of both the peaks are found to increase in the doped sample against the undoped one (cf. Table 2), which implies the presence of less-oxidized metals in the doped samples, indicating the existence of $\mathrm{Ti}^{+3}$ species within the $\mathrm{TiO}_{2}$ matrix. A closer look into the $\mathrm{Ti}^{+4} 2 \mathrm{p}_{3 / 2}$ peaks of doped sample reveals the existence of a shoulder around $457.8 \mathrm{eV}$ (cf. Figure 5(c) and Table 2), which originates from $\mathrm{Ti}^{+3}$ $2 p_{3 / 2}$ state of photoelectrons [43]. The presence of this lesser oxidation states of $\mathrm{Ti}$ ions in the doped samples indicates the formation of higher percentage of loosely bound $\mathrm{Ti}^{+3}$ $\mathrm{O}$ bonds against stronger $\mathrm{Ti}^{+4}-\mathrm{O}$ bonds, which enhances the photoelectron transfer process between anions and cations and, thus improves the photocatalytic activities of the doped nanoparticles [44]. For Ga-doped samples, Ga 3d spectrum is shown in Figure 5(d), which after deconvolution, reveals the presence of two peaks, the lower B.E. peak (at $21.3 \mathrm{eV}$ ) originates from elemental $\mathrm{Ga}$ in $\mathrm{Ga}_{2} \mathrm{O}_{3}$ and the higher one (at $22.7 \mathrm{eV}$ ) is speculated to be due to $\mathrm{Ga}-\mathrm{Ti}$ complex within the $\mathrm{TiO}_{2}$ : Ga nanoparticles. Similar unknown $\mathrm{Ga} 3 \mathrm{~d}$ peak (at $22.8 \mathrm{eV}$ B.E.) is observed by Ghita et al. [46] in their Ti-oxidized GaAs samples and speculated to be originated from Ga-Ti complex. The relative area of these two peaks (cf. Table 2) shows the lesser percentage of $\mathrm{Ga}_{2} \mathrm{O}_{3}$ formation against Ga-Ti complex and may be attributed to the greater fraction of interstitial doping with respect to substitutional doping in our highly doped $\mathrm{TiO}_{2}$ : Ga nanoparticles. This argument finds support from the EDX data (cf. Table 1), where it is found that the doped sample becomes more metal excess against the undoped sample. Ideally, the chemical formula for metal-doped $\mathrm{TiO}_{2}$ would be $\mathrm{Ti}_{1-x} \mathrm{O}_{2} \mathrm{M}_{y}$; (M is dopant ion, $x$ is substitution of Ti by $\mathrm{M}$ ions, and $y$ is doping concentration). For $100 \%$ substitutional doping of $\mathrm{M}$ ions in the Ti sites, $x$ will assume the value of $y$. Else $x<y$, when interstitial doping is also present, which is thermodynamically more practical situation. Therefore, 

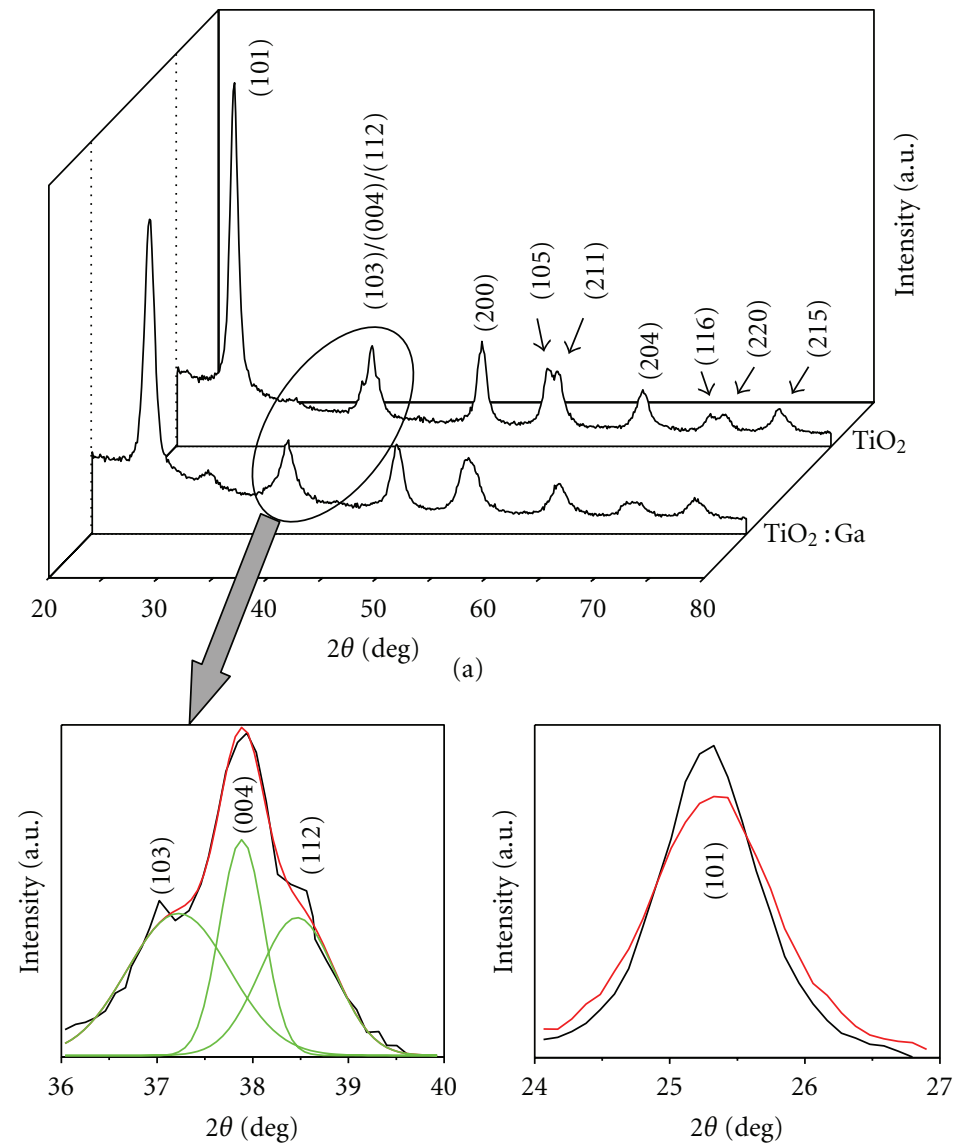

$-\mathrm{TiO}_{2}$

- $\mathrm{TiO} 2-\mathrm{Ga}$

(b)

(c)

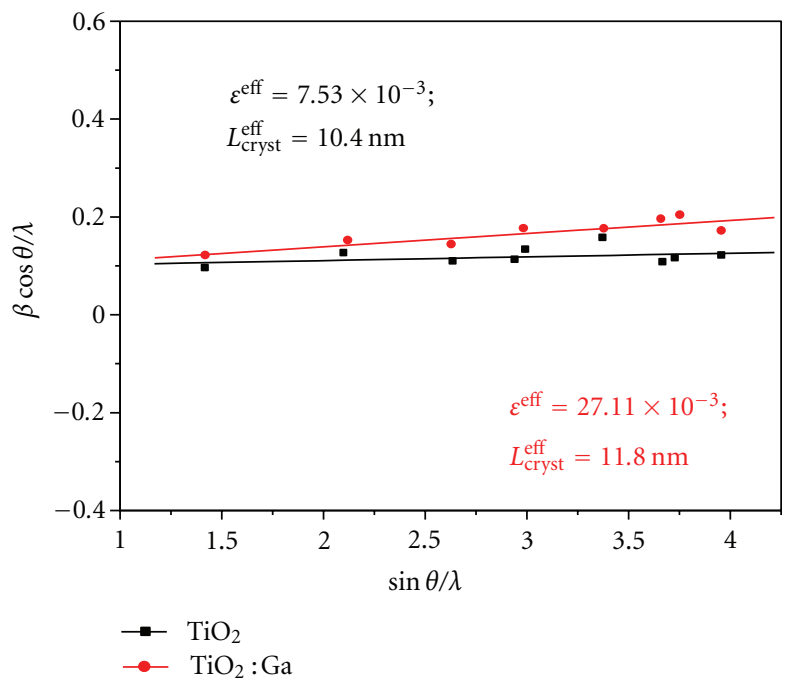

(d)

Figure 2: (a) XRD patterns of undoped and Ga-doped $\mathrm{TiO}_{2}$ nanoparticles. (b) Magnified XRD graph of the undoped $\mathrm{TiO}_{2}$ sample between $36^{\circ}$ and $40^{\circ}$ of $2 \theta$ values, showing the resolution of (103), (004), and (112) peaks after deconvolution. (c) Magnified (101) peaks of the undoped and $\mathrm{Ga}$-doped $\mathrm{TiO}_{2}$ nanoparticles showing the strain broadening effect within the doped samples. (d) Size-strain analyses of undoped and $\mathrm{Ga}$-doped $\mathrm{TiO}_{2}$ nanoparticles. 
TABLE 1: Different structural parameters of undoped and metal-doped $\mathrm{TiO}_{2}$.

\begin{tabular}{lcc}
\hline Parameters & $\mathrm{TiO}_{2}$ & $\mathrm{TiO}_{2}: \mathrm{Ga}^{2}$ \\
\hline Effective crystallite size $\left(L_{\text {cryst }}^{\text {eff }}\right)(\mathrm{nm})$ (from XRD data) & 10.4 & 11.8 \\
Effective strain $\left(\varepsilon^{\text {eff }}\right)($ from XRD data) & $7.53 \times 10^{-3}$ & $2.71 \times 10^{-2}$ \\
Average particle size $\left(L^{\text {avg }}\right)(\mathrm{nm})($ from HRTEM micrographs) & 15.3 & 17.8 \\
Atomic ratio (Ti: $:$ Ga) (from EDX data) & $33.87 \pm 0.51: 66.12 \pm 0.65$ & $33.49 \pm 0.52: 65.51 \pm 0.66: 0.99 \pm 0.047$ \\
\hline
\end{tabular}

TABLE 2: Various XPS data of $\mathrm{O}$ and Ti species within the undoped and metal-doped $\mathrm{TiO}_{2}$ nanoparticles.

\begin{tabular}{|c|c|c|c|c|}
\hline & Electronic levels & Fitting parameters & $\mathrm{TiO}_{2}$ & $\mathrm{TiO}_{2}: \mathrm{Ga}$ \\
\hline \multirow{6}{*}{ O $1 \mathrm{~s}$} & \multirow{3}{*}{$\mathrm{Ti}-\mathrm{O}$} & B.E. $(\mathrm{eV})$ & 530.5 & 530.5 \\
\hline & & FWHM $(\mathrm{eV})$ & 1.02 & 1.06 \\
\hline & & $\operatorname{Area}^{1}(\%)$ & 66.0 & 58.4 \\
\hline & \multirow{3}{*}{$\mathrm{Ti}-\mathrm{OH}$} & B.E. $(\mathrm{eV})$ & 531.7 & 531.9 \\
\hline & & FWHM $(\mathrm{eV})$ & 2.77 & 3.34 \\
\hline & & Area $^{1}(\%)$ & 34.0 & 41.6 \\
\hline \multirow{9}{*}{$\operatorname{Ti} 2 \mathrm{p}$} & \multirow{3}{*}{$\mathrm{Ti}^{+4} 2 \mathrm{p}_{3 / 2}$} & B.E. $(\mathrm{eV})$ & 459.3 & 459.3 \\
\hline & & FWHM $(\mathrm{eV})$ & 1.02 & 1.08 \\
\hline & & Area $^{2}(\%)$ & 69.3 & 69.1 \\
\hline & \multirow{3}{*}{$\mathrm{Ti}^{+4} 2 \mathrm{p}_{1 / 2}$} & B.E. $(\mathrm{eV})$ & 465.0 & 465.0 \\
\hline & & FWHM $(\mathrm{eV})$ & 1.68 & 1.75 \\
\hline & & Area $^{2}(\%)$ & 30.7 & 30.9 \\
\hline & \multirow{3}{*}{$\mathrm{Ti}^{+3} 2 \mathrm{p}_{3 / 2}$} & B.E. $(\mathrm{eV})$ & - & 457.8 \\
\hline & & FWHM $(\mathrm{eV})$ & - & 1.02 \\
\hline & & $\operatorname{Area}^{3}(\%)$ & 一 & 6.1 \\
\hline \multirow{6}{*}{ Ga 3d } & \multirow{3}{*}{ Due to elemental $\mathrm{Ga}$ in $\mathrm{Ga}^{+3}-\mathrm{O}$} & B.E. $(\mathrm{eV})$ & - & 21.3 \\
\hline & & FWHM $(\mathrm{eV})$ & - & 5.27 \\
\hline & & Area $^{4}$ & - & 33.3 \\
\hline & \multirow{3}{*}{ Due to formation of Ga-Ti complex } & B.E. $(\mathrm{eV})$ & - & 22.7 \\
\hline & & FWHM $(\mathrm{eV})$ & - & 2.74 \\
\hline & & Area $^{4}$ & - & 66.7 \\
\hline
\end{tabular}

${ }^{1}$ With respect to the entire area under the $\mathrm{O} 1 \mathrm{~s}$ curve.

${ }^{2}$ With respect to the entire area under the Ti $2 p$ curve.

${ }^{3}$ With respect to the area under the Ti $2 \mathrm{p}_{3 / 2}$ curve only.

${ }^{4}$ With respect to the entire area under the Ga $3 \mathrm{~d}$ curve(s).

the presence of excess nonstoichiometric metal content in our Ga-doped samples indicates a larger fraction of interstitial doping within the $\mathrm{TiO}_{2}$ matrix with respect to substitutional doping. It should also be mentioned in this connection that, in the XPS survey spectra of undoped and metal-doped samples (not shown here), presence of C $1 \mathrm{~s}$ peaks is also observed, indicating the existence of small $\mathrm{C}$ contents within our samples, which may be attributed to the adventitious hydrocarbon from specimen handling and (or) pumping oil of the XPS system.

3.3. Optical Characterizations. Raman spectra of undoped and $\mathrm{Ga}$-doped $\mathrm{TiO}_{2}$ nanoparticles are shown in Figures 6(a) and 6(b), respectively. The peaks placed at 145, 398, 517, and $639 \mathrm{~cm}^{-1}$ (indexed as "A") for both the spectra are typical characteristics of the anatase phase of $\mathrm{TiO}_{2}$, thus corroborating the XRD data [37]. A small peak at $318 \mathrm{~cm}^{-1}$ is observed in the doped sample and speculated to be originating from vibrations of $\mathrm{Ga}_{2} \mathrm{O}_{3}$, as observed previously by others as well for $\beta-\mathrm{Ga}_{2} \mathrm{O}_{3}[47,48]$, thus supporting the XPS data of our doped samples showing the presence of $\mathrm{Ga}_{2} \mathrm{O}_{3}$ within the $\mathrm{TiO}_{2}$ matrix. The spectral variations of diffuse reflectance $(R)$ of undoped and Ga-doped $\mathrm{TiO}_{2}$ nanoparticles are shown in Figure 6(c). For undoped and doped samples, the strong absorption edge, which corresponds to the near-band-edge emission, is found to be less than $400 \mathrm{~nm}$ and typical of anatase $\mathrm{TiO}_{2}$. But a relative comparison of the visible parts of the reflectance spectra of both the samples (cf. Inset-(i) of Figure 6(c)) depicts slight absorption into the visible region for the doped samples, owing to the charge-transfer between the Ga $d$ electrons and the $\mathrm{TiO}_{2}$ conduction band, as shown schematically in Figure 6(d). Apparently, metal doping creates a defect level within the bandgap of $\mathrm{TiO}_{2}$ and electrons can be excited from the defect state to the $\mathrm{TiO}_{2}$ conduction band by 


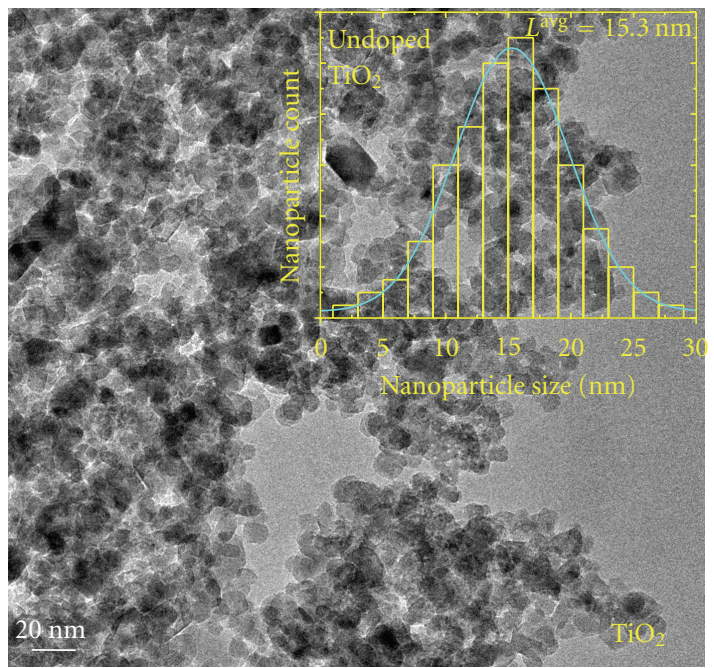

(a)

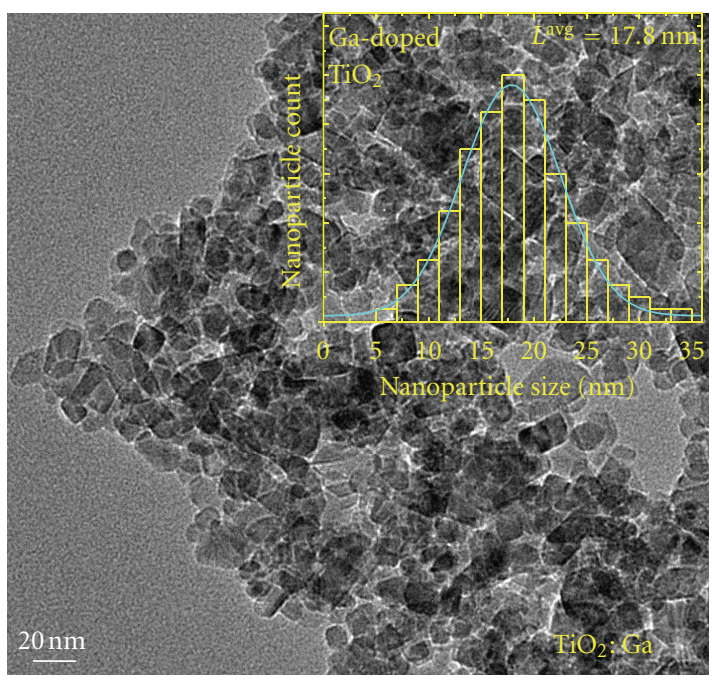

(c)

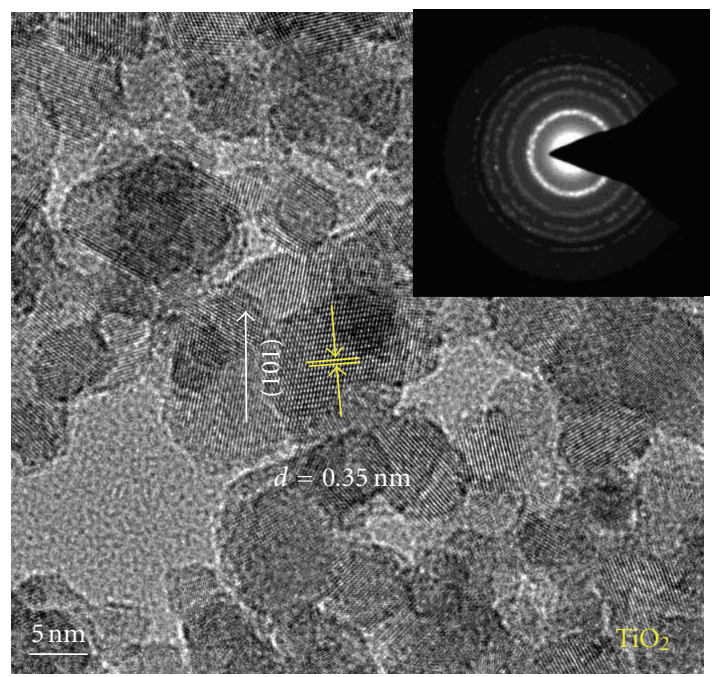

(b)

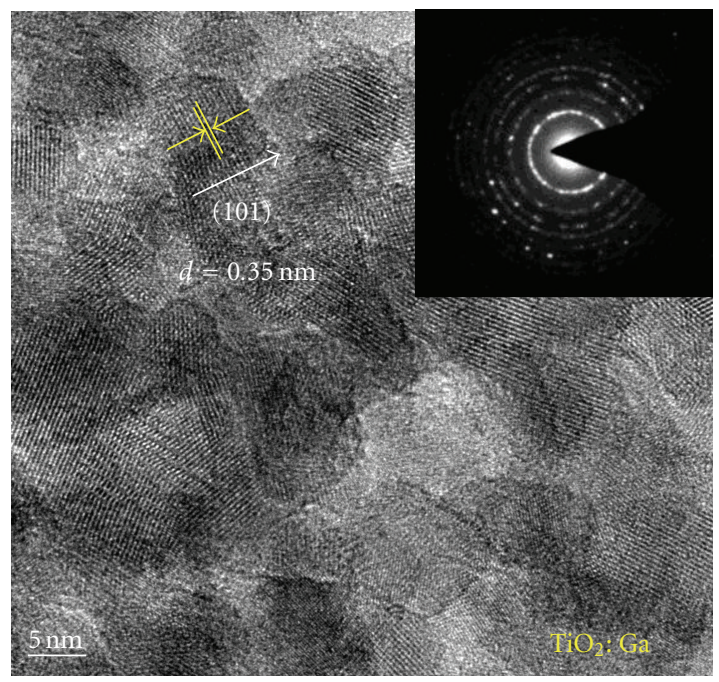

(d)

Figure 3: HRTEM micrographs of (a)/(b) undoped $\mathrm{TiO}_{2}$ and (c)/(d) $\mathrm{TiO}_{2}: \mathrm{Ga}$ at two different magnifications. Insets of (a)/(c) are the corresponding size distributions of nanoparticles. Insets of $(b) /(d)$ are the SAED patterns of undoped and Ga-doped TiO ${ }_{2}$ nanoparticles, respectively.

photons with energy $\left(h \nu_{D}\right)$ less than the bandgap energy $\left(h v_{G}\right)$, thus expanding the active region of solar spectrum for photocatalytic activity of $\mathrm{TiO}_{2}$ into the visible range. Additionally, the metal doping creates trapping centers for electrons to decrease the electron-hole recombination during irradiation to enhance the photoactivity [4]. To determine the exact bandgap values of two types of nanoparticles, an approximate relation between $R$, absorption coefficient $(\alpha)$, and scattering coefficient $(s)$, based on Kubelka-Munk theory, is adopted, assuming no transmission within the powdered samples of few millimeters thickness [49],

$$
\alpha=\frac{s}{2}\left(\frac{[1-R]^{2}}{R}\right) .
$$

Although both $\alpha$ and $s$ are functions of the energy of incident radiation $(h \nu)$, but at the region of strong absorption, $s$ is far less wavelength dependent than $\alpha$ and, hence, can be considered as constant at the onset of absorption edge. To determine the bandgap values, a graph between $(\alpha h \nu)^{2}$ and $h \nu$ is plotted at and around the fundamental absorption region (cf. inset-(ii) of Figure 6(c)), which clearly shows that the fundamental bandgaps of both the samples are identical and fall at $3.32 \mathrm{eV}$. This indicates no size effect in our undoped and $\mathrm{Ga}$-doped $\mathrm{TiO}_{2}$ nanoparticles, as depicted from the HRTEM analysis.

3.4. Photocatalytic Activity. The role of Ga-doped $\mathrm{TiO}_{2}$ nanoparticles as efficient photocatalyst is determined by the photocatalytic degradation of $\mathrm{R}^{\mathrm{h}} \mathrm{B}$ under UV light at 


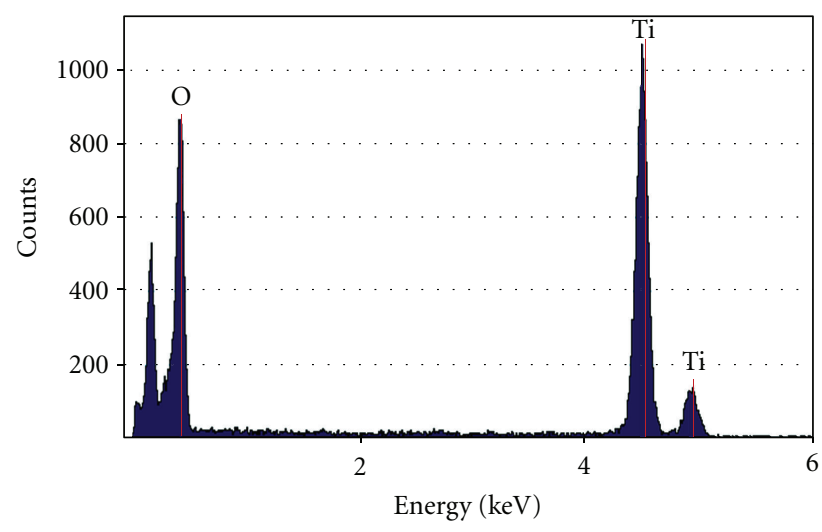

- 16.59.18 acquire EDX acquire HAADF area 1

(a)

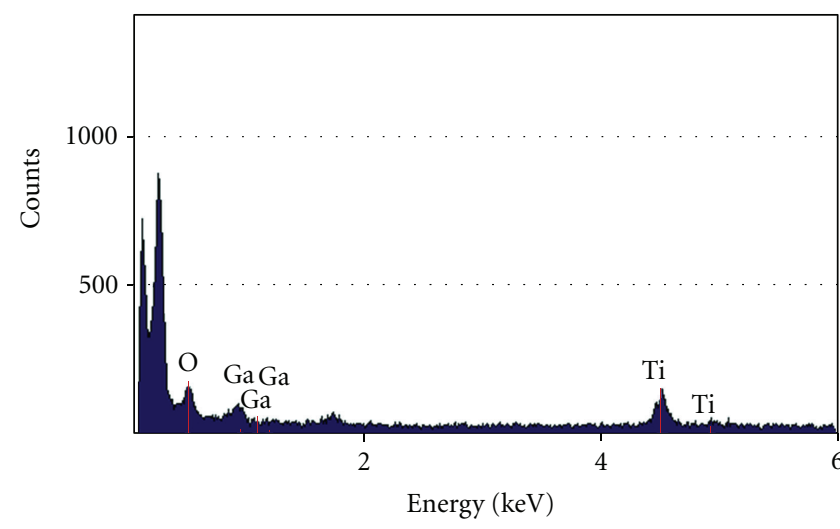

- 17.27.08 acquire EDX acquire HAADF point 1

(b)

Figure 4: EDX analyses of (a) undoped and (b) Ga-doped $\mathrm{TiO}_{2}$ nanoparticles, indicating the presence of elemental Ti, $\mathrm{O}$, and Ga.

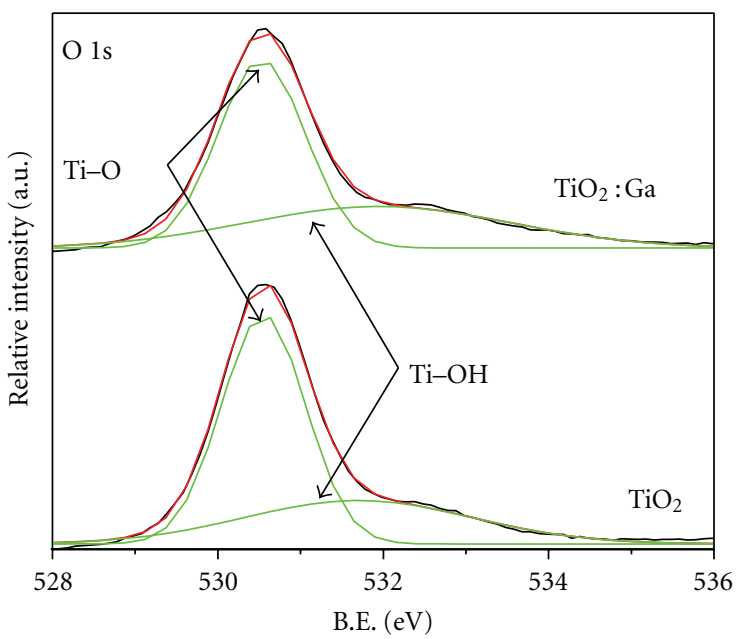

(a)

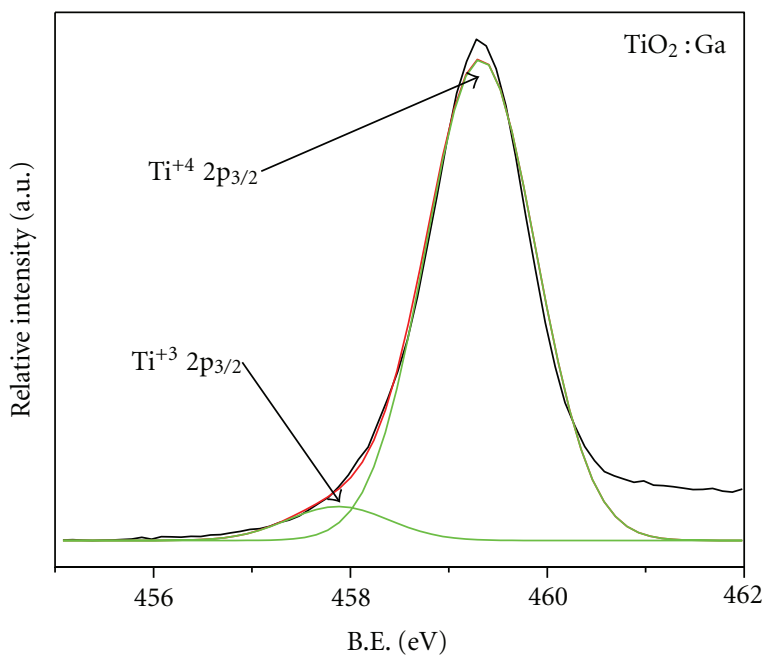

(c)

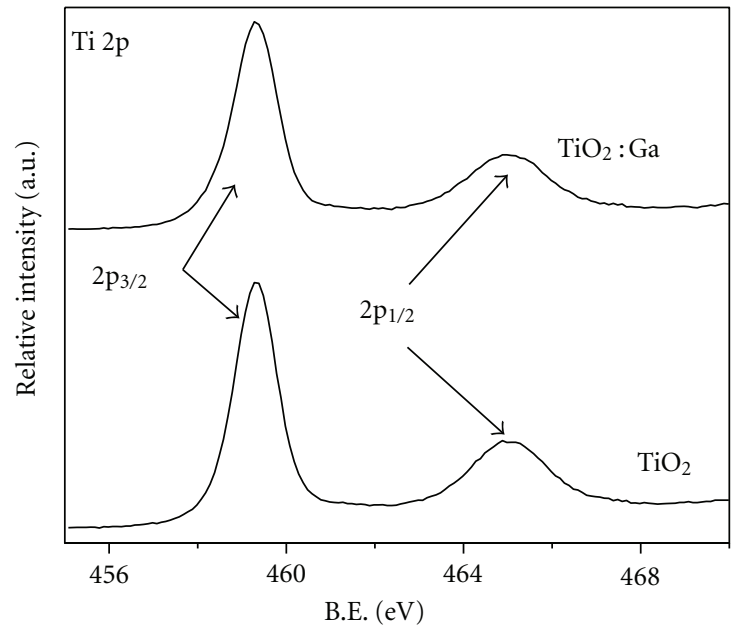

(b)

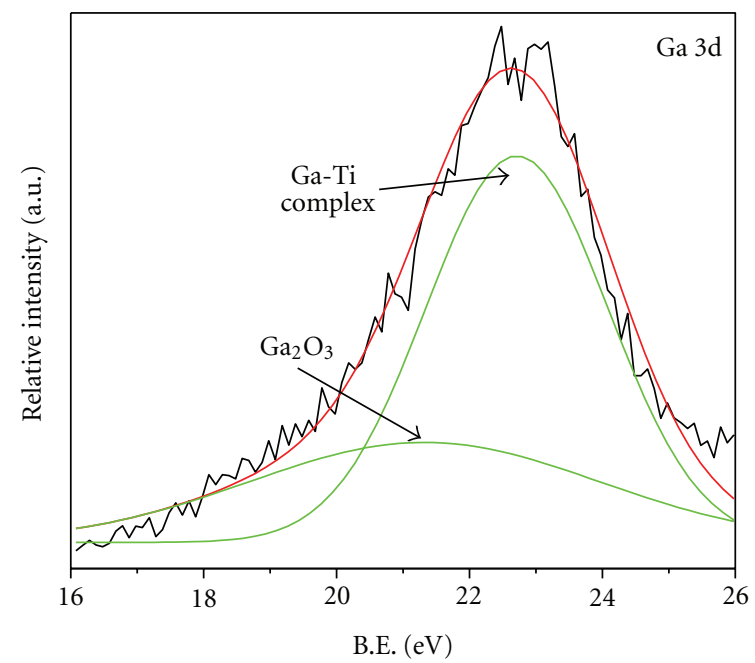

(d)

Figure 5: XPS spectra of (a) O 1s, (b) Ti 2p, (d) Ga 3d photoelectrons in undoped and Ga-doped $\mathrm{TiO}_{2}$ nanoparticles. (c) Deconvolution of Ti $2 p$ peaks of doped samples to show the existence of $\mathrm{Ti}^{+4}$ and $\mathrm{Ti}^{+3}$ ions. 
different irradiation times, and corresponding time effluence of the absorption spectra of the degraded dye solution is shown in Figure 7(a). The characteristics absorption peak intensity of $\mathrm{R}^{\mathrm{h}} \mathrm{B}$ at $554.1 \mathrm{~nm}$ is shown to be significantly decreased within $2 \mathrm{hrs}$ of irradiation, and the decoloration of the dye is completed within $3 \mathrm{hrs}$, as shown by the digital photographs of the dye solutions in the inset of Figure 7(a). The overall degradation time is lesser than that of previously reported degradation results of $\mathrm{R}^{\mathrm{h}} \mathrm{B}$ through $\mathrm{TiO}_{2}$ photocatalyst [50], indicating higher efficiency of degradation of our Ga-doped $\mathrm{TiO}_{2}$ nanoparticles. Also, a slight blue-shift of the absorption peak with an increase in time indicates the formation of some $\mathrm{N}$-de-ethylated intermediates during photodegradation of $\mathrm{R}^{\mathrm{h}} \mathrm{B}$, as reported by others as well [51]. The entire photocatalytic process for organic dye degradation is furnished as follows $[3,4]$.

$$
\mathrm{TiO}_{2}:\left.\mathrm{Ga} \stackrel{h v_{\text {in }}>h \nu_{D}}{\longrightarrow} \mathrm{e}^{-}\right|_{\text {at } \mathrm{CB}}+\left.h^{+}\right|_{\text {at } \mathrm{VB},}
$$

$$
\begin{aligned}
& \left.h^{+}\right|_{\text {at } \mathrm{VB}}+\mathrm{H}_{2} \mathrm{O} \longrightarrow \cdot{ }^{\bullet} \mathrm{OH}+\mathrm{H}^{+}, \\
& \left.h^{+}\right|_{\text {at } \mathrm{VB}}+\mathrm{OH}^{-} \longrightarrow \cdot \mathrm{OH}, \\
& \left.e^{-}\right|_{\text {at } \mathrm{CB}}+\mathrm{O}_{2} \longrightarrow \cdot \mathrm{O}_{2}^{-} \stackrel{\mathrm{H}_{2} \mathrm{O}}{\longrightarrow} \cdot \mathrm{OOH}+\mathrm{OH}^{-}, \\
& \left.e^{-}\right|_{\text {at } \mathrm{CB}}+\cdot \mathrm{OOH} \stackrel{\mathrm{H}_{2} \mathrm{O}}{\longrightarrow} \mathrm{H}_{2} \mathrm{O}_{2}+\mathrm{OH}^{-}, \\
& \cdot \mathrm{OOH}+\cdot{ }^{\bullet} \mathrm{OH} \longrightarrow \mathrm{H}_{2} \mathrm{O}_{2}+\mathrm{OH}^{-}, \\
& \left.e^{-}\right|_{\text {at } \mathrm{CB}}+\mathrm{H}_{2} \mathrm{O}_{2} \longrightarrow \cdot{ }^{\cdot} \mathrm{OH}+\mathrm{OH}^{-}, \\
& \cdot \mathrm{O}_{2}{ }^{-}+\mathrm{H}_{2} \mathrm{O}_{2} \longrightarrow \cdot{ }^{\circ} \mathrm{OH}+\mathrm{OH}^{-}+\mathrm{O}_{2},
\end{aligned}
$$

The incident photons, having energy $\left(h \nu_{\text {in }}\right)$ greater than the threshold $\left(h \nu_{D}\right)$, generate electron-hole pairs at the nanoparticle surface (7), a large part of which takes part in the photocatalytic process because of the suppression of $e^{-}-h^{+}$recombination by charge trapping of the defect levels generated by Ga doping. Depending upon the exact conditions, the holes at the valence band and electrons at the conduction band react with water and adsorbed oxygen to produce hydroxyl radicals $\left({ }^{\circ} \mathrm{OH}\right)$ and superoxide anion radicals $\left(\bullet^{\circ} \mathrm{O}_{2}^{-}\right)$, respectively, through some other products like $\mathrm{OH}^{-},{ }^{\circ} \mathrm{OOH}, \mathrm{H}_{2} \mathrm{O}_{2}$, and $\mathrm{O}_{2}(8)$, (9). Finally, these radicals with high redox oxidizing potential decompose the organic dye into $\mathrm{CO}_{2}, \mathrm{H}_{2} \mathrm{O}$, and other inorganic nontoxic products (10). A schematic representation of the proposed mechanism is shown in Figure 6(d). Further, it has been reported previously $[52,53]$ that the ${ }^{\cdot} \mathrm{OH}$ radical, which is considered to be one of the main species with high redox oxidizing potential to decompose the organic dye, can be detected by photoluminescence (PL) technique and quantitatively scaled to compare the photocatalytic performance of various photocatalysts. According to this methodology, phase pure anatase $\mathrm{TiO}_{2}$ (along with Degussa P-25) showed very high formation rate of ${ }^{\bullet} \mathrm{OH}$, so also better photoactivity [52]. Therefore, a detailed PL analysis of Ga-doped $\mathrm{TiO}_{2}$ as a function of doping concentration is necessary to correlate the ${ }^{\circ} \mathrm{OH}$ formation rate and the photocatalysis of our nanoparticles, which is further course of our research.

To quantitatively determine the performance of the photocatalyst, the percentage degradation $(\% d)$ is calculated by measuring relative decrease in the dye concentration against the initial value by estimating the peak absorbance of the absorption spectra of the dye solution at different irradiation times according to the following relation:

$$
\% d=\left[1-\frac{A_{\text {dye }}^{\tau}}{A_{\text {dye }}^{0}}\right] \times 100,
$$

where $A_{\text {dye }}^{0}$ and $A_{\text {dye }}^{\tau}$ are the peak absorbance of dye solution at initial concentration and after irradiation time $\tau$, respectively. The degradation is found to be $50 \%, 80 \%$, and $90 \%$ after irradiation times of $1 \mathrm{hr}, 2 \mathrm{hr}$, and $3 \mathrm{hr}$, respectively. It is well known that the photocatalytic degradation kinetics follow the Langmuir-Hinshelwood model [54], which at low dye concentration can be approximated to an apparent 1storder kinetic reaction according to the following relation [54]:

$$
-\ln \left(\frac{C_{\text {dye }}^{\tau}}{C_{\text {dye }}^{0}}\right)=k^{\mathrm{app}} \tau,
$$

where $C_{\text {dye }}^{0}$ and $C_{\text {dye }}^{\tau}$ are the dye concentrations at initial and at irradiation time $\tau$ and $k^{\text {app }}$ is the apparent 1st-order rate constant. A plot of $\ln \left(C_{\mathrm{dye}}^{0} / C_{\text {dye }}^{\tau}\right)$ versus $\tau$ will be a straight line, slope of which will carry the information of

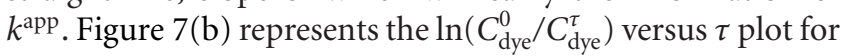
our samples, and the value of $k^{\text {app }}$ is obtained as $1.3 \times$ $10^{-2} \mathrm{~min}^{-1}$, which is found to be better than the previously reported values [50] of similar initial $\mathrm{R}^{\mathrm{h}} \mathrm{B}$ concentrations, 


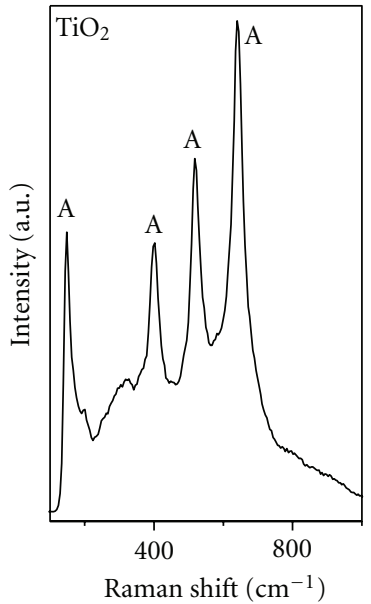

(a)

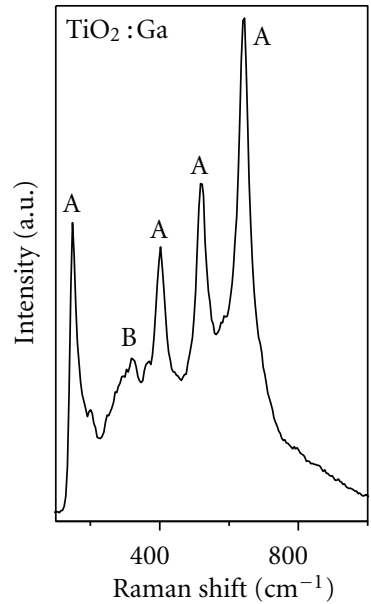

(b)

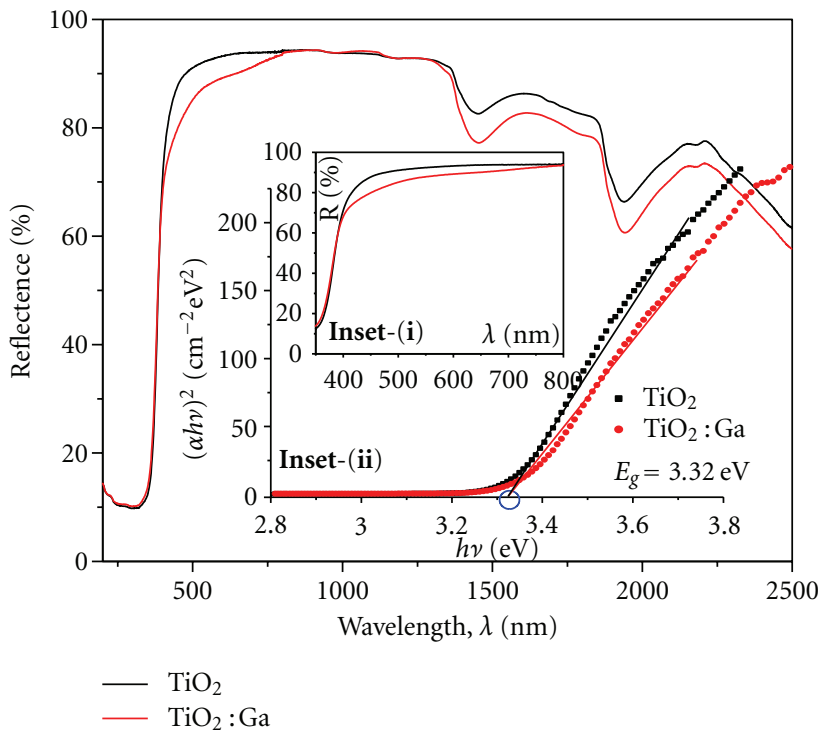

(c)

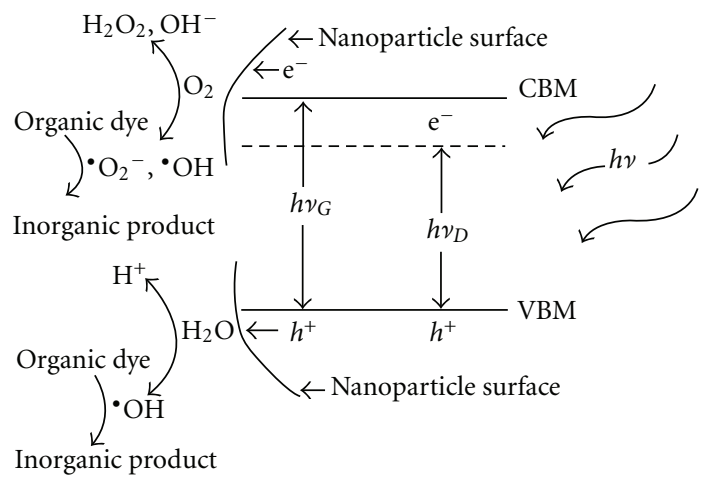

(d)

Figure 6: Raman spectra of (a) undoped, (b) Ga-doped $\mathrm{TiO}_{2}$ nanoparticles. Peaks indexed as " $\mathrm{A}$ " are originating from vibrations associated with anatase $\mathrm{TiO}_{2}$, whereas the peak indexed as " $\mathrm{B}$ " in the doped sample is from $\mathrm{Ga}_{2} \mathrm{O}_{3}$. (c) UV-Vis-NIR diffuse reflectance spectra of undoped and $\mathrm{Ga}$-doped $\mathrm{TiO}_{2}$ nanoparticles. Inset (i) represents the visible part of reflectance spectrum, and inset (ii) represents the direct bandgap calculations of undoped and $\mathrm{Ga}$-doped $\mathrm{TiO}_{2}$ nanoparticles, (d) approximate energy level diagram of doped $\mathrm{TiO}_{2}$ showing the defect level generation for improved photoactivity and the photocatalytic degradation mechanism (the diagram is not to the scale).

photocatalyzed with $\mathrm{TiO}_{2}$, indicating better photoactivity of our Ga-doped $\mathrm{TiO}_{2}$ nanoparticles. Also, to compare the photocatalytic performance of our sample (1.0 at.\% Gadoped $\mathrm{TiO}_{2}$ nanoparticles) with standard Degussa P-25 (asreceived) samples, we have observed an $80 \%$ degradation of $\mathrm{R}^{\mathrm{h}} \mathrm{B}$ within 120 min of irradiation, which is better than the Degussa $\mathrm{P}-25 \mathrm{TiO}_{2}$ powders, where $\mathrm{R}^{\mathrm{h}} \mathrm{B}$ is found to be degraded upto $80-90 \%$ within 150 min [55]. Further, the results are found to be better for 2.0 at.\% Ga-doped samples against Degussa P-25, where we have observed almost 90\% degradation of $\mathrm{R}^{\mathrm{h}} \mathrm{B}$ within 90 min of irradiation.

As far as the effect of doping concentrations on the photocatalytic activity of the Ga-doped $\mathrm{TiO}_{2}$ nanoparticles is concerned, we have observed a gradual increase in the photoactivity of the nanoparticles from 0.1 at.\% to 2.0 at.\% Ga-doped samples, beyond which the photoactivity started to decrease. It is speculated that, beyond the optimal doping concentration, the $\mathrm{Ga}^{+3}$ ions may not act favorably as the charge trapping centers to reduce the electronhole recombination, rather become recombination centers through "quantum tunneling" to affect the photoactivity significantly, as observed previously for $\mathrm{Fe}^{+3}$-doped $\mathrm{TiO}_{2}$ nanomaterials $[41,56]$. Similar effect is also observed for Ga-doped $\mathrm{TiO}_{2}$ nanoparticles as well $[36,37]$, where the photoactivity is found to reach an optimum value for a certain dopant concentration ( $2 \mathrm{~mol} . \%$ or $2-5$ at $\%)$. In the current paper, we have reported all the data against 1.0 at $\%$ Ga doping, but a detailed study on the effect of doping concentration on the photocatalytic activity of $\mathrm{Ga}-\mathrm{TiO}_{2}$ for photodegradation of organic dye (such as $\mathrm{R}^{\mathrm{h}} \mathrm{B}$, Methyl Orange, Orange-II, etc.) is underway and will be reported in due course. 


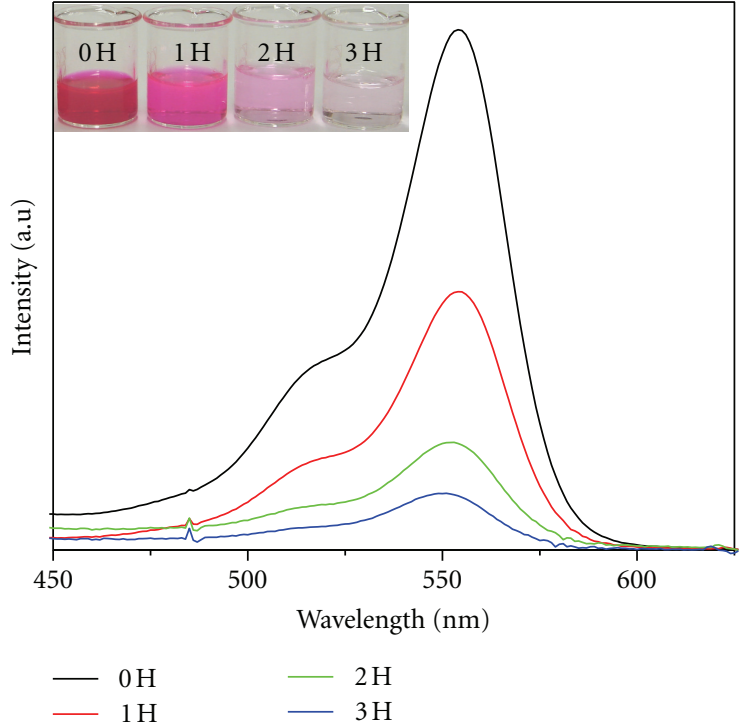

(a)

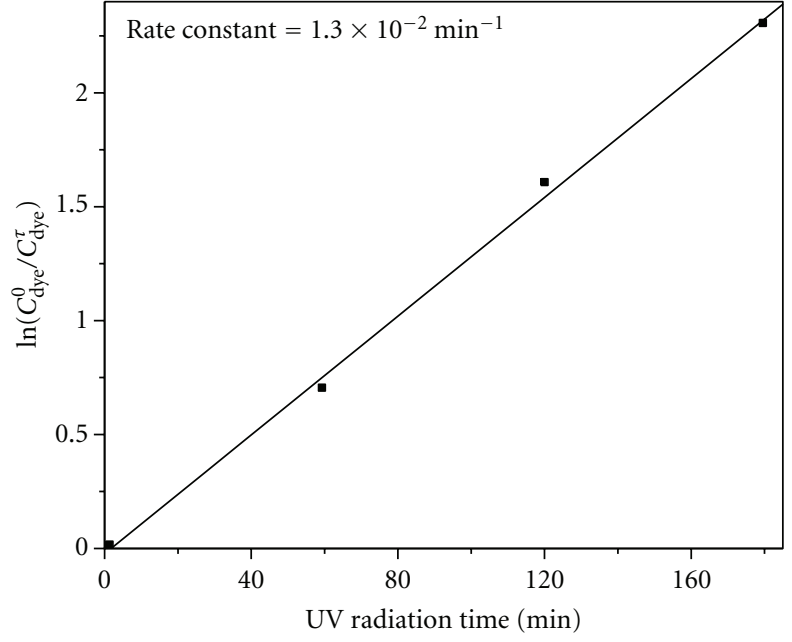

(b)

Figure 7: (a) Time effluence on photocatalytic degradation of Rhodamine B dye using $\mathrm{TiO}_{2}$ : Ga nanoparticles as the photocatalyst under UV irradiation. Inset represents the digital photographs of dye solution at different irradiation times to show color change due to photocatalytic degradation of $\mathrm{R}^{\mathrm{h}} \mathrm{B}$. (b) Pseudo-first-order kinetic plots and apparent rate constant of $\mathrm{R}^{\mathrm{h}} \mathrm{B}$ degradation.

\section{Conclusions}

Photocatalytic degradation of organic dye solution (Rhodamine $\mathrm{B}$ ) is performed using $\mathrm{Ga}$-doped $\mathrm{TiO}_{2}$ nanoparticles as the photocatalyst. The nanoparticles are synthesized via sol-gel deposition process by using titanium isopropoxide and gallium oxide as the starting materials. XRD and Raman measurements confirm the pure anatase phase formation of the nanoparticles. Size-strain analysis shows that the doped samples are slightly strained due to the presence of $\mathrm{Ga}$ ions within $\mathrm{TiO}_{2}$ matrix either as substitutional and (or) interstitial dopants. The nanoparticle size is found to be around $15 \mathrm{~nm}$ and confirmed via HRTEM imaging. XPS analysis shows the presence of $\mathrm{Ti}^{+3}$ and surface titanol groups, which enhance the photoactivity of the nanoparticles. Optical reflectance measurements showed a slight red-shift of the bandgap of the doped sample due to the formation of defect state within the bandgap of $\mathrm{TiO}_{2}$ to improve the photocatalytic activity of $\mathrm{TiO}_{2}$. Degradation of dye solution is done under UV irradiation and found to be highly efficient. The apparent 1st-order rate constant is found to be around $1.3 \times 10^{-2} \mathrm{~min}^{-1}$, which is relatively higher than the previously reported values of $\mathrm{TiO}_{2}$-assisted photodegradation of $\mathrm{R}^{\mathrm{h}} \mathrm{B}$ with similar initial concentrations. The cost-effective, sol-gel-derived $\mathrm{TiO}_{2}$ : Ga nanoparticles can be used efficiently for light-assisted oxidation of toxic organic molecules in the surface water for environmental remediation.

\section{Acknowledgments}

Financial support of the World Class University Grant no. R32-2008-000-20082-0 of the Korea Research Foundation is acknowledged. The authors are also grateful to Ji-Hye Park and Dong-Ju Lim of UNIST Central Research Facilities for Raman and XPS characterizations, respectively.

\section{References}

[1] A. N. Banerjee, "The design, fabrication, and photocatalytic utility of nanostructured semiconductors: focus on $\mathrm{TiO}_{2}$ based nanostructures," Nanotechnology, Science and Applications, vol. 4, no. 1, pp. 35-65, 2011.

[2] A. Fujishima and K. Honda, "Electrochemical photolysis of water at a semiconductor electrode," Nature, vol. 238, no. 5358, pp. 37-38, 1972.

[3] A. L. Linsebigler, G. Lu, and J. T. Yates, "Photocatalysis on $\mathrm{TiO}_{2}$ surfaces: principles, mechanisms, and selected results," Chemical Reviews, vol. 95, no. 3, pp. 735-758, 1995.

[4] A. Zaleska, "Doped- $\mathrm{TiO}_{2}$ : a review," Recent Patents on Engineering, vol. 2, no. 3, pp. 157-164, 2008.

[5] K. Shankar, J. I. Basham, N. K. Allam et al., "Recent advances In the use of $\mathrm{TiO}_{2}$ nanotube and nanowire arrays for oxidative photoelectrochemistry," Journal of Physical Chemistry C, vol. 113, no. 16, pp. 6327-6359, 2009.

[6] K. Juodkazis, J. Juodkazyte, E. Jelmakas et al., "Photoelectrolysis of water: Solar hydrogen-achievements and perspectives," Optic Express, vol. 18, no. 102, pp. A147-A160, 2010.

[7] X. Chen and S. S. Mao, "Titanium dioxide nanomaterials: synthesis, properties, modifications and applications," Chemical Reviews, vol. 107, no. 7, pp. 2891-2959, 2007.

[8] A. Wold, "Photocatalytic properties of $\mathrm{TiO}_{2}$," Chemistry of Materials, vol. 5, no. 3, pp. 280-283, 1993.

[9] U. Diebold, "The surface science of titanium dioxide," Surface Science Reports, vol. 48, no. 5-8, pp. 53-229, 2003.

[10] S. Liu, J. Yu, and M. Jaroniec, "Anatase $\mathrm{TiO}_{2}$ with dominant high-energy 001 facets: synthesis, properties, and applications," Chemistry of Materials, vol. 23, pp. 4085-4093, 2011. 
[11] Q. Xiang, J. Yu, and M. Jaroniec, "Graphene-based semiconductor photocatalysts," Chemical Society Reviews, vol. 41, pp. 782-796, 2012.

[12] J. G. Yu, H. G. Yu, B. Cheng, X. J. Zhao, J. C. Yu, and W. K. Ho, "The effect of calcination temperature on the surface microstructure and photocatalytic activity of $\mathrm{TiO}_{2}$ thin films prepared by liquid phase deposition," Journal of Physical Chemistry B, vol. 107, no. 50, pp. 13871-13879, 2003.

[13] J. Yu, J. Xiong, B. Cheng, and S. Liu, "Fabrication and characterization of $\mathrm{Ag}-\mathrm{TiO}_{2}$ multiphase nanocomposite thin films with enhanced photocatalytic activity," Applied Catalysis B: Environmental, vol. 60, no. 3-4, pp. 211-221, 2005.

[14] L. Vegard, "Results of crystal analysis," Philosophical Magazine, vol. 32, pp. 505-515, 1916.

[15] B. O'Regan and M. Grätzel, "A low-cost, high-efficiency solar cell based on dye-sensitized colloidal $\mathrm{TiO}_{2}$ films," Nature, vol. 353, no. 6346, pp. 737-740, 1991.

[16] H. Tang, K. Prasad, R. Sanjinés, and F. Lévy, “ $\mathrm{TiO}_{2}$ anatase thin films as gas sensors," Sensors and Actuators B, vol. 26, no. 1-3, pp. 71-75, 1995.

[17] M. A. Grela, M. A. Brusa, and A. J. Colussi, "Harnessing excess photon energy in photoinduced surface electron transfer between salicylate and illuminated titanium dioxide nanoparticles," Journal of Physical Chemistry B, vol. 101, no. 51, pp. 10986-10989, 1997.

[18] Y. Wang, Y. Hao, H. Cheng et al., "Photoelectrochemistry of transition metal-ion-doped $\mathrm{TiO}_{2}$ nanocrystalline electrodes and higher solar cell conversion efficiency based on $\mathrm{Zn}^{2+}$ doped $\mathrm{TiO}_{2}$ electrode," Journal of Materials Science, vol. 34, no. 12, pp. 2773-2779, 1999.

[19] D. Dvoranová, V. Brezová, M. Mazúr, and M. A. Malati, "Investigations of metal-doped titanium dioxide photocatalysts," Applied Catalysis B, vol. 37, no. 2, pp. 91-105, 2002.

[20] A. Fuerte, M. D. Hernández-Alonso, A. J. Maira et al., "Visible light-activated nanosized doped- $\mathrm{TiO}_{2}$ photocatalysts," Chemical Communications, no. 24, pp. 2718-2719, 2001.

[21] N. H. Hong, J. Sakai, W. Prellier, and A. Ruyter, "Room temperature ferromagnetism in laser ablated transition-metaldoped $\mathrm{TiO}_{2}$ thin films on various types of substrates," Journal of Physics D, vol. 38, no. 6, pp. 816-821, 2005.

[22] A. W. Xu, Y. Gao, and H. Q. Liu, "The preparation, characterization, and their photocatalytic activities of rare-earth-doped $\mathrm{TiO}_{2}$ nanoparticles," Journal of Catalysis, vol. 207, no. 2, pp. 151-157, 2002.

[23] J. Li and C. Z. Hua, "Hollowing Sn-doped $\mathrm{TiO}_{2}$ nanospheres via Ostwald ripening," Journal of the American Chemical Society, vol. 129, no. 51, pp. 15839-15847, 2007.

[24] Y. Shen, T. Xiong, T. Li, and K. Yang, "Tungsten and nitrogen co-doped $\mathrm{TiO}_{2}$ nano-powders with strong visible light response," Applied Catalysis B: Environmental, vol. 83, no. 3-4, pp. 177-185, 2008.

[25] K. Wilke and H. D. Breuer, "The influence of transition metal doping on the physical and photocatalytic properties of titania," Journal of Photochemistry and Photobiology A, vol. 121, no. 1, pp. 49-53, 1999.

[26] M. Melemeni, D. Stamatakis, N. P. Xekoukoulotakis, D. Mantzavinos, and N. Kalogerakis, "Disinfection of municipal wastewater by $\mathrm{TiO}_{2}$ photocatalysis with UV-A, visible and solar irradiation and BDD electrolysis," Global Nest Journal, vol. 11, no. 3, pp. 357-363, 2009.

[27] D. F. Ollis, "Photocatalytic purification and remediation of contaminated air and water," C R Academic Science of Paris, Chemical, vol. 3, no. 6, pp. 405-411, 2000.
[28] A. Mills and S. Le Hunte, "An overview of semiconductor photocatalysis," Journal of Photochemistry and Photobiology A, vol. 108, no. 1, pp. 1-35, 1997.

[29] M. R. Hoffmann, S. T. Martin, W. Choi, and D. W. Bahnemann, "Environmental applications of semiconductor photocatalysis," Chemical Reviews, vol. 95, no. 1, pp. 69-96, 1995.

[30] K. Kabra, R. Chaudhury, and R. L. Sawney, "Treatment of hazardous organic and inorganic compounds through aqueousphase photocatalysis: a review," Indian Engineering Chemical Research, vol. 43, no. 24, pp. 7683-7696, 2004.

[31] J. M. Herrmann, "Heterogeneous photocatalysis: state of the art and present applications," Topics in Catalysis, vol. 34, no. 1-4, pp. 49-65, 2005.

[32] G. Palmisano, V. Augugliaro, M. Pagliaro, and L. Palmisano, "Photocatalysis: a promising route for 21st century organic chemistry," Chemical Communications, no. 33, pp. 3425-3437, 2007.

[33] A. P. Zhang and Y. P. Sun, "Photocatalytic killing effect of $\mathrm{TiO}_{2}$ nanoparticles on Ls-174-t human colon carcinoma cells," World Journal of Gastroenterology, vol. 10, no. 21, pp. 31913193, 2004.

[34] A. Fujishima, T. N. Rao, and D. A. Tryk, "Titanium dioxide photocatalysis," Journal of Photochemistry and Photobiology C, vol. 1, no. 1, pp. 1-21, 2000.

[35] C. Mccullagh, J. M. C. Robertson, D. W. Bahnemann, and P. K. J. Robertson, "The application of $\mathrm{TiO}_{2}$ photocatalysis for disinfection of water contaminated with pathogenic microorganisms: a review," Research on Chemical Intermediates, vol. 33, no. 3-5, pp. 359-375, 2007.

[36] J. Chae, J. Lee, J. H. Jeong, and M. Kang, "Hydrogen production from photo splitting of water using the Ga-incorporated $\mathrm{TiO}_{2} \mathrm{~s}$ prepared by a solvothermal method and their characteristics," Bulletin of Korean Chemical Society, vol. 30, no. 2, pp. 302-308, 2009.

[37] C. M. Whang, J. G. Kim, E. Y. Kim, Y. H. Kim, and W. I. Lee, "Effect of $\mathrm{Co}, \mathrm{Ga}$, and $\mathrm{Nd}$ additions on the photocatalytic properties of $\mathrm{TiO}_{2}$ nanopowders," Glass Physics and Chemistry, vol. 31, no. 3, pp. 390-395, 2005.

[38] S. Song, C. Wang, F. Hong, Z. He, Q. Cai, and J. Chen, "Gallium- and iodine-co-doped titanium dioxide for photocatalytic degradation of 2-chlorophenol in aqueous solution: Role of gallium," Applied Surface Science, vol. 257, no. 8, pp. 3427-3432, 2011.

[39] J. Zhou, Y. Zhang, X. S. Zhao, and A. K. Ray, "Photodegradation of benzoic acid over metal-doped $\mathrm{TiO}_{2}$," Industrial and Engineering Chemistry Research, vol. 45, no. 10, pp. 3503-3511, 2006.

[40] T. Okajima, T. Yamamoto, M. Kunisu, S. Yoshioka, I. Tanaka, and N. Umesaki, "Dilute Ga dopant in $\mathrm{TiO}_{2}$ by X-ray absorption near-edge structure," Japanese Journal of Applied Physics Part 1, vol. 45, no. 9, pp. 7028-7031, 2006.

[41] W. Choi, A. Termin, and M. R. Hoffmann, "The role of metal ion dopants in quantum-sized $\mathrm{TiO}_{2}$ : correlation between photoreactivity and charge carrier recombination dynamics," Journal of Physical Chemistry, vol. 98, no. 51, pp. 13669-13679, 1994.

[42] B. D. Cullity, Elements of X-ray Diffraction, Addison-Wesley, Reading, Mass, USA, 1978.

[43] R. Wang, N. Sakai, A. Fujishima, T. Watanabe, and K. Hashimoto, "Studies of surface wettability conversion on $\mathrm{TiO}_{2}$ single-crystal surfaces," Journal of Physical Chemistry B, vol. 103 , no. 12 , pp. 2188-2194, 1999. 
[44] N. L. Wu, M. S. Lee, Z. J. Pon, and J. Z. Hsu, "Effect of calcination atmosphere on $\mathrm{TiO}_{2}$ photocatalysis in hydrogen production from methanol/water solution," Journal of Photochemistry and Photobiology A, vol. 163, no. 1-2, pp. 277-280, 2004.

[45] J. C. Yu, J. Yu, and J. Zhao, "Enhanced photocatalytic activity of mesoporous and ordinary $\mathrm{TiO}_{2}$ thin films by sulfuric acid treatment," Applied Catalysis B: Environmental, vol. 36, no. 1, pp. 31-43, 2002.

[46] R. V. Ghita, C. Logofatu, C. Negrila et al., "XPS study of Ti/oxidized GaAs interface," Journal of Optoelectronics and Advanced Materials, vol. 8, no. 1, pp. 31-36, 2006.

[47] R. Rao, A. M. Rao, B. Xu, J. Dong, S. Sharma, and M. K. Sunkara, "Blueshifted Raman scattering and its correlation with the [110] growth direction in gallium oxide nanowires," Journal of Applied Physics, vol. 98, no. 9, Article ID 094312, 2005.

[48] P. W. Wang, Y. P. Song, X. Z. Zhang, J. Xu, and D. P. $\mathrm{Yu}$, "Transformation from $\beta-\mathrm{Ga}_{2} \mathrm{O}_{3}$ to $\mathrm{GaN}$ nanowires via nitridation," Chinese Physics Letters, vol. 25, no. 3, pp. 10381041, 2008.

[49] J. D. Lindberg and D. G. Snyder, "Determination of the optical absorption coefficient of powdered materials whose particle size distribution and refractive indices are unknown," Applied Optics, vol. 12, no. 3, pp. 573-578, 1973.

[50] N. Barka, S. Qourzal, A. Assabbane, A. Nounah, and Y. AitIchou, "Factors influencing the photocatalytic degradation of Rhodamine $\mathrm{B}$ by $\mathrm{TiO}_{2}$-coated non-woven paper," Journal of Photochemistry and Photobiology A, vol. 195, no. 2-3, pp. 346351, 2008.

[51] K. Yu, S. Yang, H. He, C. Sun, C. Gu, and Y. Ju, "Visible light-driven photocatalytic degradation of rhodamine $\mathrm{B}$ over $\mathrm{NaBiO}_{3}$ : pathways and mechanism," Journal of Physical Chemistry A, vol. 113, no. 37, pp. 10024-10032, 2009.

[52] Q. Xiang, J. Yu, and P. K. Wong, "Quantitative characterization of hydroxyl radicals produced by various photocatalysts," Journal of Colloid and Interface Science, vol. 357, no. 1, pp. 163 167, 2011.

[53] Q. Xiang, J. Yu, and M. Jaroniec, "Nitrogen and sulfur codoped $\mathrm{TiO}_{2}$ nanosheets with exposed $\{001\}$ facets: synthesis, characterization and visible-light photocatalytic activity," Physical Chemistry Chemical Physics, vol. 13, no. 11, pp. 48534861, 2011.

[54] N. Guettaï and H. Ait Amar, "Photocatalytic oxidation of methyl orange in presence of titanium dioxide in aqueous suspension. Part II: kinetics study," Desalination, vol. 185, no. 1-3, pp. 439-448, 2005.

[55] X. Qin, L. Jing, G. Tian, Y. Qu, and Y. Feng, "Enhanced photocatalytic activity for degrading Rhodamine B solution of commercial Degussa $\mathrm{P} 25 \mathrm{TiO}_{2}$ and its mechanisms," Journal of Hazardous Materials, vol. 172, no. 2-3, pp. 1168-1174, 2009.

[56] J. Yu, Q. Xiang, and M. Zhou, "Preparation, characterization and visible-light-driven photocatalytic activity of Fe-doped titania nanorods and first-principles study for electronic structures," Applied Catalysis B, vol. 90, no. 3-4, pp. 595-602, 2009. 

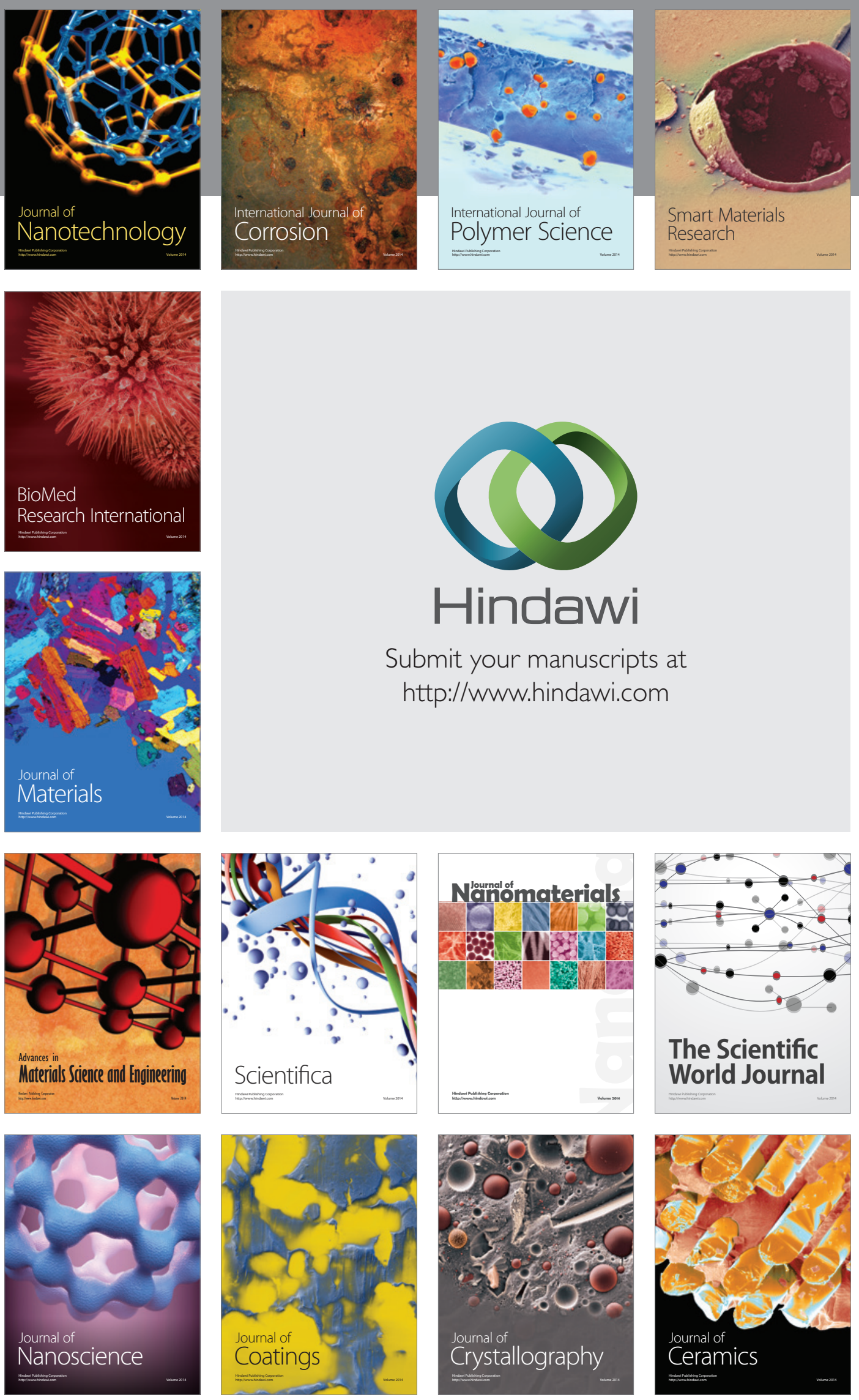

The Scientific World Journal

Submit your manuscripts at

http://www.hindawi.com

\section{World Journal}

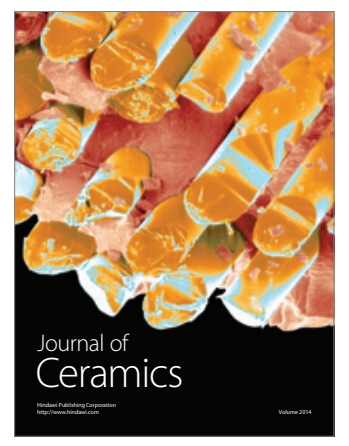

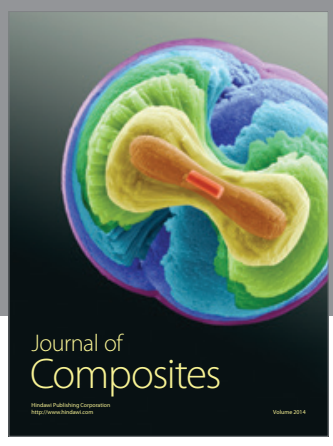
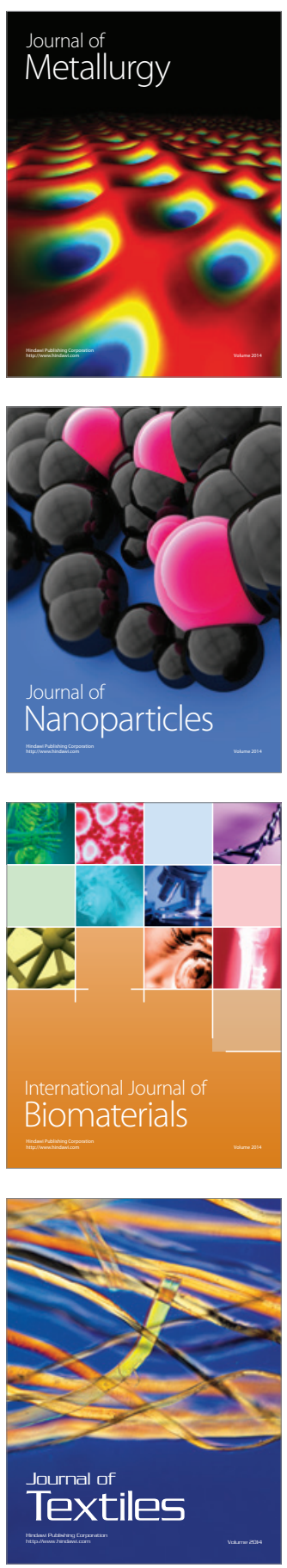